\title{
Aesthetic Object and Subject in Song Translation
}

\author{
Jian-Sheng Yang ${ }^{1}$ \\ ${ }^{1}$ English Department, College of Humanities and Foreign Languages, Xi'an University of Science and \\ Technology, Xi'an, China \\ Correspondence: Jian-Sheng Yang, College of Humanities and Foreign Languages, Xi'an University of Science \\ and Technology, No. 2,Yanta Road (Southern Section), Xi'an 710054 ,China. E-mail:18091384316@163.com
}

Received: July 14, 2014 Accepted: September 10, 2014 Online Published: November 25, 2014

doi:10.5539/ells.v4n4p25 URL: http://dx.doi.org/10.5539/ells.v4n4p25

\begin{abstract}
The translation of songs which is well accepted in the target language society owes to use of the translator's esthetic thoughts and theories. The esthetic characteristics of song lyrics make translating them much demanding. This paper, from the perspective of esthetic object and subject, illustrates the importance of deep understanding of the esthetic objective and the roles played by esthetic subject in song translation.
\end{abstract}

Keywords: esthetic object, esthetic subject, song translation

\section{Introduction}

The process of translating songs, from aesthetic perspective, can be interpreted as such an aesthetic activity involving the aesthetic subject's (the translator's) comprehension, scanning, structuring, processing and representation or, as Jiang Qiuxia (2002) put it, Image-Gestalt actualization. The process of representation is based on the integral cognition and comprehension of the translator about the aesthetic object, the source text or precisely, the original song. The translated version can be a new entirety beyond each part of the original; it is also a whole aesthetic experience of the translator about the artistic form.

\section{Aesthetic Object: Song Text with Due Consideration Given to Its Melody}

As for aesthetic object, ancient Chinese believed that it was a kind of objective reality composed of form, image and spirit which was regarded as the foremost. Aesthetic experience about the object means to master the deep or inner beauty of spirit beyond the superficial form and image, and only in this way can the inner lasting appeal or essence of the aesthetic object be cognized and the authentic beauty be comprehended. Aesthetic objects can be classified into three types: material forms, materialized forms and aestheticized result of spiritual/mental activities (Liu, 2011, p. 142). Obviously, literature, art and other artistic forms are of the third type. The aesthetic object is subjectified and reflects the prescription of the subject. This kind of subjectification is regarded as the basic attribute.

As far as song translation is concerned, the aesthetic object is the song, which includes its lyrics and tune. So when doing the work, the translator has to view the two aspects as a whole. As a result, the translator has to be capable of appreciating the beauty of both language and music, and meanwhile, pay sufficient attention to the restriction of music.

\subsection{The Aesthetic Features or the Beauty of Song Lyrics}

The aesthetic features or the beauty of song lyrics lies in three aspects: formal, phonological and dynamic. The formal beauty of song lyrics means they are beautiful in form. In effect, formal beauty is of great significance in poetry, which is one of Xu Yuanchong's Three-Beauty Principle in translating poetry. Take a glimpse of thousands of songs, no matter what languages they are, and it can be recognized that most of them are evenly arranged in order, with antithetic or parallel constructions because the features of lyric texts dovetail Xu's viewpoint of the beauty in form. See the famous film song Edelweiss in ex 1.1a:

Ex 1.1a (version 1 by Xue Fan)

Edelweiss, edelweiss

xue rong hua, xue rong hua

Every morning you greet me

qing chen ying zhe wo kai fang

Small and white, clean and bright

xiao er bai, jie er liang 
You look happy to meet me

Blossom of snow may you bloom and grow

Bloom and grow forever

Edelweiss, edelweiss

Bless my homeland forever xiang wo kuai le de yao huang

bai xue ban de hua er yuan ni fen fang

yong yuan kai hua sheng zhang

xue rong hua, xue rong hua

yong yuan zhu fu wo jia xiang

The song is named after the edelweiss, which is a white flower found high in the Alps. Edelweiss is a show-tune, from the 1959 Rodgers and Hammerstein musical The Sound of Music. It is sung by Captain Georg Ludwig von Trapp and his family during the concert near the end of Act II as a defiant statement of Austrian patriotism faced with the pressure pressed on him to join the navy of Nazi Germany. In the 1965 film adaptation, the song is also sung by the Captain earlier in the film when he rediscovers music and a love for his children. The song shows its beauty in form since its division of syllables is arranged in this way:

\begin{tabular}{|c|l|l|l|l|l|l|l|l|l|c|}
\hline Line & \multicolumn{7}{|c|}{ Division of syllables } & Num \\
\hline 1 & E & del & weiss & e & del & weiss & & & & 6 \\
\hline 2 & Eve & ry & mor & ning & you & greet & me & & & 7 \\
\hline 3 & Small & and & white & clean & and & bright & & & & 6 \\
\hline 4 & You & look & hap & py & to & meet & me & & & 7 \\
\hline 5 & Blos & som & of & snow & may & you & bloom & and & grow & 9 \\
\hline 6 & Bloom & and & grow & for & ev & er & & & & 6 \\
\hline 7 & E & del & weiss & e & del & weiss & & & & 6 \\
\hline 8 & Bless & my & home & land & for & ev & er & & & 7 \\
\hline
\end{tabular}

The table above shows that the lyric lines follow the pattern: 67679667 according to the division of syllables. This pattern, in fact, is a kind of symmetrical pattern. In addition, "small and white" and "clean and bright" are basically antithetic. "Edelweiss, edelweiss" is repetitive structure. All mentioned here is in accordance with the requirement of aesthetics. As for the Chinese version by Xue Fan, it is perfectly compatible with the original lyrics and melody, with each character matching along with each English syllable. Meanwhile, he uses Chinese couplets in the version to maintain the beauty of form. The analysis above is based on just one stanza of a single song. Most songs, in effect, have two or more stanzas, with each one consistent with the same or similar pattern. In this case, if seen from an overall point of view, the structure is like a architectural complex, with some similarly structured buildings arranged in order, indicating a kind of integrated beauty (Xu, 2000).

Secondly, song lyrics are beautiful in phonology. The phonological beauty of lyrics is mainly presented by means of rhyme and rhythm. Rhyme refers to the correspondence of two or more words with similar-sounding final syllables placed so as to echo one another. It partly seems to be appreciated simply as a repeating pattern that is pleased to hear. It is widely used by poets and occasionally by prose writers to suit their own purposes, to produce aesthetic and musical sounds pleasing the reader's senses and to unify and establish a poem's stanzaic form. End rhyme is the most common type of rhyme in English poetry, meaning the last word in the lines, rhyme with each other. Nowadays perhaps unrhymed songs are more common than formerly in English, "but in many traditions rhyme is still strong." (Low, 2008). Rhyme is of vital importance in translating song lyrics since there are hardly any lyrics without rhyme; rhyme can color the song text, intensify its artistic conception and emotion, and arouse sympathy of the audience. Songs that rhyme are easier to be sung, remembered and spread. Take the song Edelweiss in Ex1.1a for instance and it will be found that the rhyme pattern is prominent: ai/i:/ai/i: (abab) and $\partial \mathrm{u} / \mathrm{\partial} / \mathrm{ai} / \mathrm{\partial} / \mathrm{(acbc)}$. Similarly, in Xue's version, another rhymed pattern is adopted, that is "ang" in Chinese Pinyin, which belongs to Jiang-yang Rhyme ${ }^{1}$. Rhythm, as was mentioned previously, is music's pattern in time. It symbolizes another aspect of the lyrics' musicality besides rhyme. The rhythmic patterns of modern song lyrics, on the one hand, break out the constraint of classical poetry and follow no fixed styles. On the other, they never discard the regularity of rhythm; instead, they follow, as Xu Ziqiang (2000) put it, the "supreme rule of formal 
beauty - unified diversity", through which the flexible rhythmic patterns are demonstrated in a unanimous way.

Thirdly, it is the dynamic beauty of song lyrics. Music is an art of time, which, with the continuation of time, demonstrates every part of the work successively in a dynamic way. Since song is one accomplishing means of music, the dynamic nature is also revealed in song lyrics. The dynamic beauty of lyrics not only conforms to the musicality, but it also enhances the spirit and vitality of the work, and even expands its poetic space of imagination. Take the famous American Christmas song Jingle Bells (excerpt) for example:

Ex 1.1b (translated by Deng Yingyi )

Dashing through the snow

In a one- horse open sleigh

Over the fields we go

Laughing all the way

Bells on bobtails way

Making spirits bright

What fun it is to ride and sing

A sleighing song tonight

$\mathrm{OH}$, Jingle bells, jingle bells,

Jingle all the way

Oh, what fun it is to ride

In a one-horse open sleigh chong po da feng xue

wo men zuo zai xue qiao shang

fei ben guo tian ye

yi lu xiao sheng lang

ling er xiang ding dang

jing shen duo huan chang

jin wan hua xue duo you qu

ba hua xue ge er chang

o, ding ding dang, ding ding dang

yi lu ling sheng xiang

$o$, jin wan hua xue duo you qu

wo men zuo zai xue qiao shang

The song lyrics in Ex1.1b are alive with motion and sounds (e.g., the underlined words), and thus are particularly appropriate for performance by music. The rhythm pattern is light and lively; the melody is smooth and easy. When listening to, even reading it, one may imagine that he or she is sitting on the sleigh, singing, laughing and riding over the field covered with snow. Of course, talking about the dynamic beauty of lyrics does not mean that song text denies static notions. As Xu Ziqiang (2000) put it, motion and stillness is a pair of unity of opposites, with one serving as a foil for the other. Therefore, it is impossible as well as useless to describe only one of them.

\subsection{Aesthetic Thoughts of Music}

Music is an art that, to some degree, permeates every human society. Music is a protean because it lends itself easily to alliances with words, as in song, and with physical movement, as in dance. During the whole history, music has played an important role in ceremonies and drama and has been credited with the capacity to reflect and influence people's emotion. Popular culture has consistently developed these possibilities, most obviously today by means of radio, movie, television, and the musical theatre. The implications of the using of music in psychotherapy, geriatrics, and advertising bear out a faith in its power to influence human action. Publications and recordings have effectively globalized music in its most significant, as well as its most trivial, manifestations.

Traditionally, the aesthetics of music or musical aesthetics studied the mathematical and cosmological dimensions of rhythmic and harmonic organization. In the eighteenth century, focus shifted from the experience of hearing music, thus to the questions about its beauty and people's enjoyment of music. In recent decades, philosophers have tended to put an emphasis on the issues besides beauty and enjoyment. For instance, music's power to express emotion has become an important issue.

It is often believed that music has the power to affect influence our emotions, wisdom and psychology; it can alleviate our loneliness or stir our passions. In ancient China, Confucius (551-479 BC) considered music to play an important place in the service of a good-ordered moral world. He thought of government and music as reflecting each other and held that only the superior man that is able to enjoy and appreciate music can be equipped to govern. Music, he believed, reveals personalities through the six emotions that it can be described as: joy, anger, sorrow, love, piety, satisfaction. According to Confucius, great music is harmonious with the whole universe. It is harmony that brings the physical world into good order. As a mirror of personality, music makes deception or impossible.

In the west, like Confucius, Plato (428-348/347 BC), took music as a part of ethics. And he was as anxious as Confucius to standard the use of particular modes i.e., arrangements of notes, like scales, owning to their 
supposed influence on men. Plato indicates in the Republic ${ }^{2}$ that music has a direct influence on human soul. Therefore, he puts forward that in the desirable regime music would be closely ruled by the state. As a strict disciplinarian, he saw a relationship between men's character and the music that can reveal his soul. Direct simplicity was best. In the $\mathrm{Laws}^{3}$, Plato declared that rhythmic and melodic complicacies were to be avoided because they resulted in depression and disorder.

Music creates divine harmony; rhythm and melody imitate the actions of heavenly bodies, thus describing the music of the spheres and revealing the moral order of the universe. Philosophers admitted and treasured music in its ethically approved forms and their concerns were mainly with the influences of music. Therefore, they considered it as a psychosociological phenomenon. It has become a strong tendency in the aesthetics of music to stress on the great importance of compositional structure.

In translating songs, the translator, as the aesthetic subject (which will be discussed in the following part), has to take the beauty of music seriously in his work, because it is his or her ability to appreciate the artistic beauty of music that counts much in the representation of the original in translation.

\section{Aesthetic Subject: The Translator, the Singer and the Audience}

The aesthetic subject in translating songs, in a broad sense, refers to the translator the singer and the audience as a whole. In this section, therefore, the topic is focused on the translator's mental structure, the singer's ease of performance and the perception or acceptance of the audience.

\subsection{The Translator's Aesthetic Psychological Structure in Song Translation}

In song translation, the aesthetic subject is the translator and the translating process, to a great extent, involves his or her psychological activity. It has been understood that translation is not just to replace one pre-formulated text with another, but involves workings of the translator's mental faculties as intermediary agents. Therefore, this section will aim at the translator's mental or psychological structure and its influence on the translating practice. Although the mental process of the translator is like, as Jiang (2002) put it, a "black box", hard to observe, it is still possible to make arguments on it, for the theory of aesthetic experience can help to provide some access to this exploration.

The translator's psychological structure in translation, also called, as Liu (2011) put it, "prestructure", includes an established psychological framework, in which the translator is ready to tackle the aesthetic information coming to him. The translator then premises his competence on the prestructure when there is something to be translated. What's more, the prestructure also includes a "sedimentary deposit", which provides his former samples of aesthetic judgment or experience and serves as a new reference when he has to make a new judgment.

When translating songs, the translator must be ready to recognize, comprehend and appreciate the beauty of the song text and the music, since it is closely related to his aesthetic self-cultivation and quality. At the same time, he makes new judgment on the song and attempts to reconstruct the artistic beauty in the mind based on his experience. In such a psychological process, the meaning of the lyrics together with the translator's aesthetic experience results in the possibility of translation. Meanwhile, the translator adjusts his established aesthetic schema to the author's so as to construct the same aesthetic feeling and to achieve the natural and effective rendering. Mao (2005) noted,

The translator's experience will become his perceptual schema in the center of his subject consciousness, on which any perceptual activities will be based. As a result, the translator's aesthetic perception goes hand in hand with his or her thoughts, education, personality and etc.

In song translation, therefore, the translator must be qualified for both literature and music and have the ability to appreciate the aesthetic beauty of the artistic work. Only in this case can a good version be rendered. Moreover, when the song is translated, the translator has to take another two aspects into account, namely, the singer's ease of performance and the acceptance of the audience, as will be discussed in the following parts.

\subsection{The singer's ease of performance}

As another aesthetic subject, the singer should, on the one hand, be clear about the meaning and spirit of the song, on the other hand, perform the translated song text to the audience. Thus the version must undoubtedly be easy to sing. This viewpoint is essential since it is closely related to the singability of song translation. So obviously, it is the experienced singers who can be viewed as the best judges of the singability of a text. Their judgments, again, are based on the thorough comprehension and perception about the aesthetic beauty of the work.

Nevertheless, in singing an English song, anyone who is aware of the sounds of English language can see that it 
is blessed with many closed syllables, and frequent clusters of consonants at the very beginning or end of words. Reciting can help to distinct consonant clusters and other places where singers will confront problems with diction. For example, the English word or phrase that gives the best semantic solution may be difficult to sing, like "strict", which has five consonants and one vowel, and that vowel is short, unsuited to a long musical note. In this case, the word may as well be replaced by "tight" with two consonants and a nice singable diphthong. Similarly, in singing a Chinese song, if the notorious examples of

$P o-j u$ and Dao-zi as in 2.1.4 appear in the translated songs, it will be quite difficult for

the singer to perform effectively, and the original artistic beauty of the song can hardly to be conveyed. For example, the following version in Ex 2.2 violates one of the two notorious kinds of taboo- $P o-j u$.

Ex 2.2

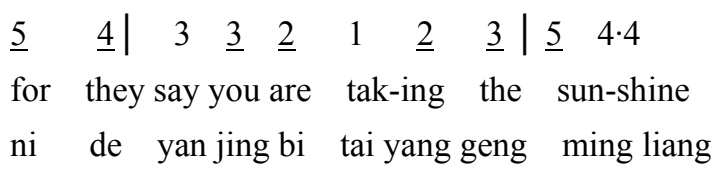

The proper division of sense-group should be ni de/yan jing/bi tai yang/geng ming liang, but when sung to the music, the version is quite like ni de yan/jing bi tai/yang geng ming liang, which will inevitably confuse the audience, as well as ruin the performance of the singer. In another version translated by Xue Fan, the lyric line has been arranged as follows:

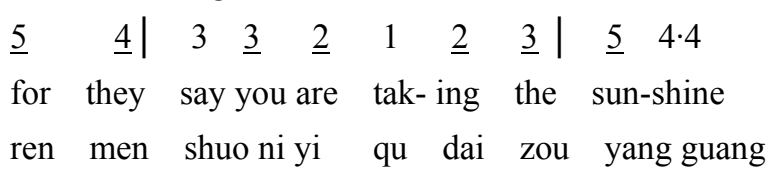

Xue's version values the aesthetic representation of the original and meanwhile gives due consideration to singability. Therefore, the Chinese lyric line is much easier to sing since it conforms to the proper division of sense-group: ren men shuo/ni yi qu/dai zou/yang guang.

So obviously, the ease of the singer's performance is determined by two aspects. First, it is the singer's aesthetic judgment, through which the singer understands the meaning, concerns the emotion and experiences the artistic conception. Second, it is the translator's aesthetic representation embodied in the target version, by which all the relevant aesthetic factors can be expressed.

\subsection{The Perception of the Audience}

There is no doubt that the audience does not stand at the same height of appreciation as the translator does. However, when the audience as a whole cannot be said to know any of the foreign languages in the song well, and would prefer to follow the translated words from their own lips to the music easily and naturally, the translation of the song is regarded as successful, for the version is perfectly perceived and accepted by the audience. The point is in accordance with the requirement of singability in song translation, as Low (2003) put it, "This places a premium on natural language, because unnaturalness demands an additional and superfluous effort from the audience".

As a matter of fact, the audience is the participant as well as the witness in the performance. As a member of the audience, he collaborates in the performance of the work and at the same time he gets to apprehend it. Besides, the assistance which the spectator provides is that of aesthetic perception which reveals the aesthetic object. As

Mikel Dufrenne (1973) put it,

if it is true, as we shall see, that the very height of aesthetic perception is found in the feeling which reveals the expressiveness of the work, a prime form of this feeling is discoverable in the kind of human warmth and emotion which a rapt crowd exudes.

Therefore the task of the translator is to maintain the same artistic beauty as well as the same effect of the original in the target language. What's more, only when the translated song is well understood by the audience can it be popularized. Of course, if the artistic beauty of the foreign song is to be perfectly conveyed, a cooperation of the translator and the singer is necessary.

\section{Conclusion}

From the above analysis, it can be concluded that the esthetic object and subject should be consistent and harmonious with each other. All the esthetic factors that the esthetic object has are the basis for the esthetic subject to translate and recreate the source song lyrics. Without the proper transmission of the esthetic factors of 
the song, the translation is not faithful. Therefore, the esthetic subject ought to make good understanding of the esthetic object and get qualified in esthetic thoughts and theories so as to overcome the barriers in song translation.

\section{References}

Dufrenne, M. (1973). The Phenomenology of Aesthetic Experience. Evanston: Northwestern University Press.

Low, P. (2008). Translating songs that rhyme. Perspectives:Studies in Translatology, 16, 1-20. http://dx.doi.org/10.1080/13670050802364437

Jiang, Q. X. (2002). The Aesthetic Process in Literary Translation: Image-G Actualization. Beijing: Commercial Press.

Liu, M. Q. (2011). The Aesthetics Translation Theories. Beijing: Foreign Language Teaching and Research Press.

Mao, R. G. (2005). Translation Aesthetics. Shanghai: Shanghai Jiaotong University Press.

Xu, Z. Q. (2000). Aesthetic Writing Lyrics. Beijing: Capital Normal University Press.

Xue, F. (2004). When We're Young - English Song 100 Songs (English and Chinese Version). Beijing: China International Broadcasting Publishing House.

Xue, F. (2002). Song Translation Theory and Practice. Wuhan: Hubei Education Press.

\section{Notes}

Note 1. Jiang-yang Rhyme refers to one of the 13 types of traditional Chinese rhyme patterns, namely, jiang yang yun. See the appendix at the end of the thesis for more information.

Note 2. The Republic (Greek: Пo $\imath \imath \tau \varepsilon i ́ \alpha$, Politeia) is a Socratic dialogue written by Plato over 380 BC about the definition of justice, the order and character of the fair city-state and the fair man. See also http://en.wikipedia.org/wiki/The_Republic_(Plato)

Note 3. The Laws is Plato's last and longest dialogue. The question asked at the beginning is "What is law?"

\section{Copyrights}

Copyright for this article is retained by the author(s), with first publication rights granted to the journal.

This is an open-access article distributed under the terms and conditions of the Creative Commons Attribution license (http://creativecommons.org/licenses/by/3.0/). 